\title{
Tempo e Pessoa no C.E.I. Aluysio de Menezes Greenhalg
}

Marcio Bressiani Zamboni

\section{Resumo:}

O que nos propomos a discutir nesse artigo é a importância do tempo para conceituar e, na medida do possível, compreender o significado "nativo" de criança enquanto pessoa (no sentido antropológico do termo) no contexto específico do Centro de Educação Infantil Aluysio de Menezes Greenhalg. Veremos como essa relação recoloca a importância central do tempo na relação da criança com seu corpo, na relação da criança com o espaço, na função do educador e na própria educação enquanto processo.

Palavras Chave: Educação, Tempo, Concepção de Pessoa, Criança 


\section{Agradecimentos:}

Gostaria de dedicar agradecimentos especiais à professora Rosângela, a Lúcia de Ângelo Sales, Diretora do Centro de Educação Infantil Aloysio de Menezes Greenhalg e aos colegas Maria Cristina Stello Leite e Otávio Mattos Câmara, sem os quais este trabalho seria impossível.

Também agradeço às professoras Cida, Cíntia, Fabiana, Ivone, Márcia, Neyde e Nirlene, a Dona Olga, a Déblas, a Célia, e aos demais professores e funcionários da GEI pela dedicação, pelo carinho e pela paciência.

Agradeço ainda a todas as crianças da escola: esperamos muitíssimo que elas descubram um dia o quanto aprendemos com elas.

As reflexões que deram origem a esse artigo são fruto do trabalho "Concepções de Pessoa no G.E.I. Aluysio de Menezes Greenhalg", desenvolvido junto a Maria Cristina Stello Leite e Otávio Mattos Câmara para a disciplina "Métodos III - Pesquisa de Campo em Antropologia", ministrada pela Professora Doutora Sylvia Caiuby Novaes, do Departamento de Antropologia da Faculdade de Filosofia, Letras e Giências Humanas da Universidade de São Paulo. O trabalho de campo elaborado pelo grupo foi realizado no Centro de Educação Infantil Aluysio de Menezes Greenhalg, localizado na Vila São Francisco (Zona Oeste de São Paulo, SP) ao longo dos meses de outubro, novembro e dezembro de 2008 e contou com a valiosa disposição de um corpo dedicado de pedagogos, professoras e funcionários.

A vida no Centro de Educação Infantil Aluysio de Menezes Greenhalg é marcada intensamente em todos os sentidos pelo tempo: entramos pela primeira vez na escola e é-nos logo anunciado que é "hora do café da manhã"; em seguida é "hora de ir para a sala". Ao entrar na sala vemos, logo à direita, um painel relacionando o nome de cada criança com sua foto e é visível o contraste entre as crianças à volta e os bebês fotografados meses antes. Logo ainda a professora diz: "Lembram da história do Grúfalo?" e em seguida é "hora de ir ao banheiro". Algumas semanas depois surpreendemo-nos com a articulação da conversa de um menino que antes não falava uma palavra.

O que nos propomos então a discutir é a importância, nesse contexto, do tempo para conceituar e, na medida do possível, compreender o significado "nativo" de criança enquanto pessoa no sentido antropológico do termo. Veremos ainda como essa relação recoloca a importância do tempo na relação da criança com seu corpo, na relação da criança com o espaço, na função do educador e na própria educação enquanto processo.

Antes de explorarmos o contexto pesquisado, vale esboçar um breve quadro teórico que localize essa problemática no campo da Antropologia.

O problema da Concepção de Pessoa encontra sua formulação clássica na obra antropológica de Marcel Mauss (I872-I950), na qual o conceito de Pessoa 
se opunha ao de Individuo (marcado por uma ideologia bastante particular, notadamente Iluminista), sendo a forma flexível como cada sistema cultural entendia o homem (ou o "agente empírico universal", na terminologia de Louis Dumont). A investigação dos diferentes significados que essa "categoria do espírito humano" (Mauss, 2007: p. 369) assumia em diferentes universos culturais, diferentes momentos históricos e mesmo diferentes contextos se torna então um problema central para a antropologia.

A problemática da Pessoa se insere neste trabalho a partir de uma leitura bastante peculiar da obra de Michel Foucault. Pensando o Centro de Educação Infantil como uma instituição disciplinar e a educação como prática, parece haver um imenso vazio em torno da criança em suas particularidades, em sua individualidade, em sua humanidade. O que é a criança diante de uma instituição que pretende formar uma determinada criança? Ou, em outras palavras, há uma concepção de criança que orienta a pratica educacional? Se sim, como se caracteriza e o quanto se afasta do Indivíduo clássico? A "criança” não é, aqui, um indivíduo incompleto, mas uma Pessoa, na formulação de Mauss.

De forma geral, foi essa a questão que orientou o trabalho "Concepções de Pessoa no G.E.I. Aluysio de Menezes Greenhalg", desenvolvido junto a Maria Cristina Stello Leite e Otávio Mattos Câmara, em 2008. O trabalho de campo sugeriu que não há em torno da criança (ao menos nesse estágio de desenvolvimento) o consenso que se poderia supor dada a solidez da estrutura institucional do ensino infantil público e que, se uma coerência existe, essa deve ser antes procurada na resultante de certo conjunto de práticas fundamentais (como a diferenciação entre gêneros e a cobrança de capacidades específicas em determinadas idades) do que num discurso nítido, sistemático e inequivocamente ativado. O presente artigo, fruto daquele trabalho, tratará de um problema mais particular, colocando essa temática em perspectiva a partir de outra categoria fundamental: o tempo.

A articulação entre tempo e pessoa aqui operada se inspira na que se encontra no artigo de Glifford Geertz "Pessoa, Tempo e Conduta em Bali" (Geertz, I998). Se naquele texto Geertz reflete sobre a dimensão social de certas categorias do pensamento humano (Tempo, Pessoa, Conduta) a partir de um "exame do aparato cultural nos termos do qual o povo de Bali define, percebe e reage às pessoas individuais" (Geertz, I998: p. I49), aqui faremos o possível para refletir sobre a importância de uma categoria particular do pensamento (tempo) para a compreensão da criança enquanto pessoa num contexto particular (educação infantil pública) a partir do exame do aparato cultural nos termos do qual indivíduos especializados inseridos nesse contexto definem, percebem e reagem a crianças particulares.

Nesse sentido, e também pelo esforço interdisciplinar que este trabalho carrega, a estrutura teórica e metodológica deste artigo deve ser bastante 
flexível. A partir de um trabalho etnográfico (observação participante) e de um problema teórico informado por uma perspectiva antropológica, a exposição e o estilo de análise devem se adaptar, na medida do possível, ao problema estudado.

Conhecemos de forma apenas genérica a bibliografia especializada da pedagogia e a estrutura institucional do ensino público, e reconhecemos que essa possa ser uma importante limitação deste trabalho. Outra ressalva que deve ser feita é que este estudo se refere especificamente à educação infantil pública (o a 6 anos), mais particularmente a um Centro de Educação Infantil ( I a 4 anos) da Zona Oeste da cidade de São Paulo. Qualquer tentativa de generalizar as conclusões deste artigo para outras dimensões da educação deve ser feita de forma extremamente cautelosa.

Devemos ainda dar destaque a algumas formulações teóricas que, embora não tenham sido apropriadas em seu sentido clássico, foram importantes para o desenvolvimento de conceitos aqui utilizados: a contradição e a complementaridade das concepções de individuo do século XVIII (universal) e XIX (particular) proposta por Simmel (2003) para pensar a relação entre disciplina e autonomia; o conceito de tempo estrutural de Evans-Pritchard (2000) para pensar a relação do tempo com a estrutura institucional; e o conceito de margem, de Mary Douglas (I996) para pensar a extensão de certas oposições para o espaço e para o corpo das crianças.

Partiremos então de uma proposta de divisão instrumental do tempo em duas dimensões distintas, mas profundamente relacionadas, uma cíclica (I) e outra linear (2).

A primeira (I) emerge da própria rotina da escola, dos seus horários, de suas atividades recorrentes. O eixo motor dessa dimensão é uma sequência de atividades estável (embora razoavelmente flexível) que se repete diariamente e orienta todo o funcionamento da escola: todo dia há um horário previsto para a chegada dos funcionários, para a chegada dos pais com as crianças, para servir o café da manhã, para brincar no pátio, para ir ao banheiro.

Há uma relação de definição recíproca entre a percepção cíclica do tempo e a distinção entre as atividades: o tempo é percebido essencialmente pela sucessão de atividades e essas se diferenciam pela sua posição no tempo.

A expressão "hora de (alguma atividade)" é a mais explícita forma de definir reciprocamente diferenciações entre tempos e atividades na relação com a criança. As próprias palavras que compõem essa expressão apontam para uma relação direta entre uma categoria de tempo e uma atividade. Para que as crianças vão para o pátio, por exemplo, a professora diz "é hora de ir para o pátio" e, para que elas se dirijam ao refeitório, diz-se "é hora do almoço". Quando uma criança deseja ficar no pátio e está prevista para aquele momento uma refeição, diz-se: "não é hora de pátio, é hora de comer". 
Poderíamos dizer que o tempo cíclico, ao organizar distinções entre atividades a partir de posições no tempo e distinções no tempo a partir de oposições entre atividades, estaria relacionado à capacidade da criança de administrar as diferentes esferas da vida (I).

A distinção entre as esferas da vida se estende para além do tempo até os espaços e objetos marcados por atividades contrastantes. Dessa forma, as oposições entre banheiro e sala de aula, refeitório e pátio, comida e brinquedo, são as próprias distinções entre a "hora de ir ao banheiro" e a "hora da lição", entre "hora de comer" e a "hora de brincar".

Há, com certeza, também um forte caráter prático/funcionalista na presença do tempo cíclico. A própria existência do Centro de Educação Infantil como instituição de educação pública provavelmente não seria viável sem a estabilidade relativa de uma sequência planejada de atividades; o trabalho da professora (em oposição ao da mãe) só é possível a partir da coordenação simultânea de várias crianças. Tratando-se, enfim, de uma instituição de caráter tipicamente burocrático, talvez a sistematização da rotina esteja mais ligada a um fator organizacional do que a uma concepção intencional de educação. De uma forma ou de outra, devo ressaltar que o que buscamos aqui é menos o caráter e a dinâmica da estrutura escolar do que os efeitos de alguns de seus aspectos (acidentais e incoerentes, talvez) sobre uma concepção peculiar de pessoa e de educação.

Há uma relação importante entre essa dimensão do tempo e o reconhecimento das próprias crianças enquanto crianças em oposição às professoras e aos funcionários: o exercício repetido das mesmas atividades e dos mesmos papéis dentro das mesmas atividades é um fator muito importante para que uma criança se sinta igual às outras e diferente dos educadores.

Se o tempo cíclico (I) se fundamenta na repetição diária de atividades, o tempo linear (2) parte da sucessão e acumulação de acontecimentos. Nesse sentido, todo fato é absolutamente particular, jamais se repete da mesma forma; cada dia é único e cumpre uma função específica no caminho sem volta que é a educação e, em última instância, a vida.

Se antes era uma posição na sequência diária de atividades o que orientava os indivíduos no tempo, é agora a posição dos indivíduos numa sequência ideal de grupos etários o que define seu papel. Tanto as professoras quanto as crianças se localizam simbolicamente em alguma fase da vida e, a partir desse ponto, orientam suas atividades.

As oposições primordiais seriam entre professores e crianças, entre os minigrupos (mais velhos - de 2 a 3 anos, aproximadamente) e o berçário (mais novos - de I a 2 anos, aproximadamente) e entre as crianças de uma mesma classe de idades diferentes. A identidade da criança, nesse sentido, se dá a partir do pertencimento a um determinado grupo etário. Dessa forma, quando uma criança 
do minigrupo se comporta de forma considerada imprópria para as expectativas sobre seu grupo etário, é recorrente que se lhe diga: "Você quer voltar para o berçário?" Certa vez, quando um menino mais novo gritava e foi acompanhado por outro mais velho, a professora disse ao segundo: "O Guilherme tudo bem, porque ele é pequeno, mas você, Vitor, francamente...”. A oposição professor/ criança não se coloca, no entanto, em momento algum como diretamente ligada à idade. Voltarei a esse ponto mais adiante.

É interessante notar como também essas oposições se fazem ver por toda parte no espaço e em objetos identificados a grupos etários: a identificação mais comum para um grupo etário é a "sala" a que pertence; as diferentes idades ocupam mesas diferentes no refeitório e as proporções das cadeirinhas e das mesas variam de acordo com a idade; idades diferentes usam banheiros distintos; quando uma criança, mesmo que acidentalmente, entra na copa das professoras, é-lhe dito "criança não pode entrar aî"; uma criança não deve pegar água no filtro das professoras e não é comum que as professoras comam nos pratos e com os talheres das crianças.

Há também uma definição recíproca entre o tempo linear e as atividades sucessivas que ele organiza: se uma concepção abstrata de idade e de "tamanho" orienta o tratamento da criança, também a "passagem do tempo" se percebe pelas mudanças físicas e comportamentais das crianças. Poderíamos, então, dizer que há uma aproximação simbólica importante entre tempo linear e a dimensão do processo educacional que diz respeito ao desenvolvimento psicofísico (2) da criança.

Podemos organizar resumidamente as oposições entre essas duas dimensões do tempo pela tabela a seguir:

\section{Tabela 1: Tempo Cíclico e Tempo Linear}

\begin{tabular}{|c|c|}
\hline I) Tempo Gíclico & 2) Tempo Linear \\
\hline Repetição & Sucessão e Acumulação \\
\hline Oposição entre "horas" & Oposição entre idades \\
\hline $\begin{array}{l}\text { Exercício das mesmas atividades e dos } \\
\text { mesmos papéis nas atividades }\end{array}$ & $\begin{array}{l}\text { Pertencimento a um determinado grupo } \\
\text { etário }\end{array}$ \\
\hline $\begin{array}{l}\text { Administração das diferentes esferas da } \\
\text { vida }\end{array}$ & Desenvolvimento Psicofísico \\
\hline
\end{tabular}


Há também numerosas relações entre as duas dimensões do tempo: se, por um lado, o tempo linear não é mais que um conjunto ou o resultado de ciclos, também os ciclos se localizam sempre em algum trecho do tempo linear. Pensando na relação com a criança, por um lado a forma de seu desenvolvimento é moldada a partir da administração das diferentes esferas de sua vida que se dá no dia após dia, e por outro a forma de administrar as esferas da vida se baseia no trecho ideal do desenvolvimento no qual a criança é localizada.

Essa relação se torna mais clara quando investigamos o caráter "natural" que é atribuído à condição e ao desenvolvimento da criança. Essa concepção se nos mostrou clara quando uma professora, ao explicar para as crianças a diferença entre uma lagarta e uma borboleta, disse simplesmente "a lagarta é a criança da borboleta" e em seguida explicou como a lagarta se transforma em borboleta, repetindo diversas vezes cada etapa do desenvolvimento ("a lagarta come-comecome”). Temos, assim, um processo peculiar que só se realiza a partir de ciclos de repetição (comer, esperar no casulo) e ciclos peculiares que se inserem em etapas específicas de um processo geral de desenvolvimento dado (lagarta, casulo, borboleta).

A condição da lagarta é, então, metáfora da condição da criança, que se caracteriza por ser essencialmente natural. O destino da criança, assim como o da lagarta, é se transformar; a educação não é mais arbitrária nem menos natural que a metamorfose da lagarta. Vale aqui também ressaltar que em nenhum momento a professora se coloca como o futuro da criança da mesma forma que não coloca a sua diferença em relação à criança como uma diferença no tempo; a professora não é a borboleta.

Esse "naturalismo" também se reflete na equivalência que se coloca entre diferentes funções do corpo e diferentes aspectos do processo educacional, vistos como partes de um grande e natural processo de desenvolvimento.

Assim, na oposição entre "horas" é extremamente comum opor as "horas" destinadas ao cumprimento de funções orgânicas básicas e universais (notadamente a alimentação, a higiene e o sono) a atividades típicas da vida na escola, como a hora de brincar no pátio, a hora da historinha ou a hora da lição. Ouvimos "não é hora de brincar, é hora de comer", ou "não é hora de ir ao banheiro, é hora da historinha", da mesma forma que ouvimos "não é hora de brincar, é hora da lição".

$\mathrm{Na}$ oposição entre idades é expressa uma equivalência entre crescimento ("tamanho") e determinadas expectativas ligadas ao aprendizado. Quando, por exemplo, uma criança especialmente nova surpreende o professor com a capacidade de executar uma tarefa que não era prevista para a sua idade, a professora lhe diz: "imagina que alguém pequeno desse jeito já faz isso!"

Há em torno dessa equivalência uma distinção "nativa" importante entre fatores tidos como espontâneos (A), que emanariam diretamente da natureza 
orgânica do homem e outros tidos como capacidades latentes que precisam ser desenvolvidas pela educação (B). A diferença pode ser percebida a partir da forma como as professoras acreditam que precisam lidar com um e com outro no processo de educação: é preciso ensinar a criança a controlar os primeiros e fornecer recursos para a criança desenvolver os segundos. Enquanto a educação age apenas sobre a forma e a qualidade dos primeiros (comer direito, não dormir bem, não crescer forte) também a própria existência dos segundos está simbolicamente em jogo (não ter educação, não saber falar, não falar direito).

O maior e mais interessante problema que essa exposição tentará discutir, mas dificilmente será capaz de esclarecer completamente, é essa ambiguidade entre o fato gritante e onipresente de que a educação é um processo intenso e complexo de construção sociocultural da criança e do ser humano e a anulação dessa dimensão pela concepção do desenvolvimento "natural" da criança. Por hora acreditamos que não poderíamos fazer mais do que sugerir a existência de uma espécie de convicção poderosa, persistente e flexível de que todas as capacidades da criança são ou espontaneamente manifestas ou de alguma forma latentes, sendo, de uma forma ou de outra, "naturais".

Podemos pensar, então, que a criança é atravessada por dois eixos: um que abrange as duas dimensões de tempo ( I e 2) e os aspectos do processo educacionais a elas vinculados (administração das diferentes esferas da vida e desenvolvimento psicofísico) e outro que separa as duas formas principais pelas quais as estratégias pedagógicas agem sobre a criança ( $\mathrm{A}$ e B , ou sobre a forma de fatores espontâneos e fatores latentes desenvolvidos pela educação).

A concepção de criança sobre a qual a educação (infantil) age seria, então, composta por quatro categorias estreitamente interligadas, cada uma das quais articulando uma dimensão de cada eixo. Seriam elas:

- AI (cíclico, espontâneo) = funções orgânicas básicas, notadamente alimentação (líquida e sólida), sono e higiene (fezes, urina, peido, catarro, vômito, salivação, arroto).

- BI (cíclico, latente) = disciplina (I) e autonomia (II) na administração das esferas da vida (discutirei os conceitos de disciplina e autonomia em breve).

-A2 (linear, espontâneo) = crescimento e demais processos de metamorfose do corpo (crescimento de dentes e cabelo, fortalecimento dos músculos, concentração de gordura).

- B2 (linear, latente) = aprendizado, no sentido amplo do termo (falar, ler, escrever, andar, cantar, desenhar, contar, desenvolvimento geral da capacidade cognitiva).

Talvez esses cruzamentos fiquem mais claros se colocados num quadro: 


\section{Tabela 2: Dimensões do Tempo e Dimensões da Educação}

\begin{tabular}{|l|l|l|}
\hline & $\begin{array}{l}\text { I) Cíclico (Administrar } \\
\text { diferentes esferas da vida) }\end{array}$ & $\begin{array}{l}\text { 2) LinEAR } \\
\text { (Desenvolvimento Psicofísico) }\end{array}$ \\
\hline A) ESPONTÂNEA & $\begin{array}{l}\text { Funções Orgânicas Básicas } \\
\text { (Alimentação, Sono, Higiene) }\end{array}$ & Grescimento \\
\hline B) LATENTE & $\begin{array}{l}\text { I) Disciplina } \\
\text { II) Autonomia }\end{array}$ & Aprendizado \\
\hline
\end{tabular}

Assim, além das equivalências entre AI e BI e entre A2 e B2 que já havíamos mencionado, podemos ver uma nova equivalência entre os dois pares horizontais: AI estaria para A2 assim como BI estaria para B2. Ou seja, da mesma forma que a necessidade de se alimentar, dormir e cumprir as funções de higiene é imprescindível para que as crianças cresçam, e o estágio de crescimento orienta quantitativa e qualitativamente o cumprimento das funções orgânicas básicas (leite materno sucedido por alimento sólido, maiores volumes de comida ingerida e excrementos liberados conforme se cresce), também é imprescindível para o aprendizado que a criança tenha autonomia e disciplina, e a forma e a intensidade na cobrança da disciplina e da autonomia devem variar de acordo com o posicionamento num estágio mais ou menos avançado do processo geral de aprendizado. Da mesma forma que ouvimos "se você não comer, não vai crescer", ouvimos "se você ficar brincando com o Guilherme Henrique, não tem como você entender o que eu estou falando, Vitor! Tem graça?"

A centralidade que a administração das diferentes esferas da vida parece assumir na rotina de um Centro de Educação Infantil pode ser relacionada com o lugar da educação infantil num processo mais amplo de educação, onde a dimensão do aprendizado parece predominar, de forma análoga à equivalência descrita: a criança precisa ser disciplinada e autônoma antes de aprender.

Torna-se necessário agora distinguir as categorias disciplina (I) e autonomia (II). A relação entre ambas combina uma estreita interdependência e uma profunda contradição. A disciplina está relacionada à capacidade da criança de obedecer imediatamente a uma orientação da professora e a autonomia à capacidade de internalizar instruções repetidas no tempo, de repeti-las sem a orientação direta da professora. Uma criança com muita disciplina e pouca autonomia não faria nada que não lhe fosse explicitamente pedido e a criança com muita autonomia e pouca disciplina cumpriria automaticamente as funções a que está acostumada, mas teria problemas para seguir novas atividades propostas pela professora. 
Mas essa distinção vai muito além disso: a disciplina (I) é essencialmente o limite, representando a igualdade e a dimensão negativa e passiva da educação: desde a identidade e o respeito até a obediência, a repreensão e o silêncio. Uma mesma estrutura permeia todas as relações ligadas à disciplina: há um todo racional que coordena partes a princípio irracionais, imprimindo-lhes coerência. A relação entre as partes é de igualdade enquanto se mantiverem dentro de limites definidos por uma instância superior.

Assim é a relação entre professora e crianças, entre a criança e seu corpo (desde funções orgânicas básicas até as próprias partes/membros do seu corpo) e entre a criança e o espaço: a criança indisciplinada equivale à comida fora do prato, ao cocô fora da privada, ao xixi fora da privada, ao catarro fora do nariz, à saliva fora da boca, ao braço fora da cama, à cadeira fora da mesa, à criança fora da fila, à criança fora do círculo etc.

A relação disciplinar recoloca, então, a oposição entre criança e professor, que também aqui não se expressa explicitamente (nem como uma oposição entre idades, nem como uma oposição entre parte e todo, nem entre racional e irracional) e, consequentemente, a identidade entre as crianças, ligada ao exercício das mesmas atividades e dos mesmos papeis no interior das atividades.

A autonomia (II) é essencialmente a iniciativa, representando a liberdade e a dimensão positiva, ativa da educação: desde a diferença, a alteridade e a personalidade até a reciprocidade, o estímulo e o diálogo. A estrutura típica é de uma interação entre totalidades individuais dotadas de racionalidades próprias. A oposição fundamental é entre as crianças.

A disciplina tende a privilegiar o comportamento por assim dizer exterior da criança: mais importante do que as diferenças e a complexidade que envolvem sua subjetividade é o imperativo de que ela deve agir, física e explicitamente, no sentido indicado pela professora. A própria relação da criança com seu corpo no âmbito da disciplina trata menos da capacidade de entender o funcionamento de seu corpo do que o dever de fazê-lo funcionar dentro dos limites propostos pela professora.

O momento do "esquenta" seria especialmente interessante para pensarmos a disciplina: no interior da "hora da historinha" há, antes da professora começar a contar a história propriamente dita, uma espécie de ritual de preparação para a história. A professora diz "vamos esquentar para a historinha?" e segue, esfregando uma mão na outra (como quem as esquenta no frio) e repetindo "esquenta, esquenta, esquenta, esquenta" até dizer o nome de determinada parte do corpo, colocando em seguida as mãos na parte correspondente do próprio corpo e explicando para que essa parte foi esquentada, dando ênfase a determinada palavra que traz o teor de uma orientação. Por fim, a professora repete "Vem historinha, vem", gesticulando como quem chama alguém para 
perto e por fim diz, em tom animado, "chegou a historinha!" e começa em seguida a história. As crianças repetem os gestos e tentam repetir as palavras. A sequência observada foi a seguinte:

Esquenta, esquenta, esquenta, esquenta

A orelha para ouvir a historinha

Esquenta, esquenta, esquenta, esquenta

O bumbum para ficar sentadinho

Esquenta, esquenta, esquenta, esquenta

A boca para ficar quietinho

Vem historinha, vem, vem historinha, vem

Chegou a historinha!

Podemos enxergar com alguma clareza a correspondência entre a relação da professora com as crianças e a das crianças com as partes do seu corpo. A dimensão cíclica pode ser percebida tanto na repetição diária desse momento como na repetição de cada etapa no interior do evento. O caráter passivo da disciplina pode ser percebido pelo teor das instruções (ouvir sentado e quieto). Por fim, a relação entre disciplina e aprendizado se coloca: a disciplina do corpo e dos sentidos deve preceder e acompanhar o momento do aprendizado (historinha).

A autonomia, ao contrário, preocupa-se especialmente com a interioridade e a subjetividade da criança, importando para ela menos a forma e os resultados da ação da criança e mais sua capacidade de interiorizar o sentido dessa ação, sendo capaz de discernir sobre a adequação de realizá-la ou não em situações mais ou menos correspondentes.

O processo de fixação do nome das crianças pode ser um bom caminho para entendermos a autonomia. Há, em todos os momentos, uma insistência imensa por parte das professoras de tratar todas as crianças pelo nome. É impressionante como no berçário a grande maioria das crianças fala poucas palavras, mas sabe inequivocamente o próprio nome e o nome de seus colegas. Gerta vez uma criança chamou outra pelo nome errado. A resposta da professora foi imediata e indignada "Gustavo, por que você chamou ele de Guilherme? Ele não é o Guilherme, é o Kayky! Kayky, fala para ele: eu não sou o Guilherme, eu sou o Kayky!” A percepção de diferenças na relação da criança com os colegas é, nesse sentido, mediada em todos os momentos pelo nome.

O nome é a expressão máxima da autonomia, de tudo que há de único e subjetivo na criança e no curso particular de seu desenvolvimento: cada avanço individual, cada mudança, cada erro, cada desvio, cada aptidão, cada dificuldade são acompanhados pelo nome. O nome seria, então, uma importante ferramenta na conexão entre tempo cíclico e linear, permitindo relacionar peculiaridades 
nas atividades diárias a destinos específicos no desenvolvimento da criança.

Por fim, o nome recoloca a relação complexa de complementaridade e contradição entre autonomia e disciplina: o nome, se por um lado é expressão das particularidades inconvenientes à disciplina, por outro é imprescindível para que se restabeleça a disciplina em situações de desvio. Uma situação característica desse conflito ocorreu numa segunda-feira, quando a professora decidiu ler uma história que, por acaso, havia sido contada a uma menina por sua mãe, em casa, na noite anterior. Durante a história, a menina ficou especialmente agitada, acabou levantando e adiantou, em palavras confusas, o enredo da história. A resposta da professora foi intensa: "Katharina, você vai sentar e ouvir a história como todo mundo, que você não é diferente de ninguém”. Katharina sentou e ouviu a história em silêncio. A professora agiu pela coordenação disciplinar do todo, mas sua ação recaiu sobre um agente individual autônomo.

As oposições "nativas" que envolvem a disciplina são essencialmente as que se colocam entre a criança bem ou mal "comportada", entre a criança "boazinha" e a "ruim" e entre a "bonita" e a "sem graça". Especialmente a concepção de "comportamento" traz com clareza a noção de limite (até mesmo físico) que envolve a disciplina.

A autonomia se expressa nas oposições "nativas" entre a criança "lerda" e a "esperta" e entre a criança "devagar" e a "rápida". A metáfora com ritmos aponta para uma relação peculiar entre a autonomia e aprendizado: a primeira teria o poder de definir o ritmo de desenvolvimento do segundo. Devemos lembrar aqui que também o estágio em que a criança é localizada no decurso ideal de um processo geral de aprendizado é usado, em resposta, para definir as cobranças e expectativas sobre a autonomia.

Uma última oposição pode ser pensada: o espaço da disciplina é essencialmente o espaço da escola: é na sala de aula que se coloca a oposição entre criança e professor e a identidade das crianças. A autonomia, ao contrario, se testa em casa, onde há o constante perigo de dissolução da capacidade de administração das diferentes esferas da vida tão laboriosa e insistentemente construída, onde o aprendizado pode ser estrangulado, desnorteado, subvertido.

Podemos, para facilitar a compreensão, organizar resumidamente as oposições entre disciplina e autonomia num quadro:

\section{Tabela 3: Disciplina e Autonomia}

\begin{tabular}{|l|l|}
\hline I) DisciPLINA & II) AuTONOMIA \\
\hline Seguir imediatamente instruções & Internalizar instruções \\
\hline Limite & Iniciativa \\
\hline
\end{tabular}




\begin{tabular}{|l|l|}
\hline Imitação, Igualdade & Discernimento, Liberdade \\
\hline $\begin{array}{l}\text { Identidade } \\
\text { (oposição a uma instância superior) }\end{array}$ & $\begin{array}{l}\text { Particularidade } \\
\text { (oposição entre conjuntos particulares) }\end{array}$ \\
\hline Negativa, passividade & Positiva, atividade \\
\hline Exterior, forma e resultados da ação & Interior, intenções e motivações da ação \\
\hline Incide sobre a forma do aprendizado & Incide sobre o ritmo do aprendizado \\
\hline $\begin{array}{l}\text { Todo racional imprime coerência a partes a a } \\
\text { princípio irracionais }\end{array}$ & $\begin{array}{l}\text { Interação de totalidades individuais } \\
\text { dotadas de racionalidade própria }\end{array}$ \\
\hline $\begin{array}{l}\text { Relação professor/criança, criança/corpo e e } \\
\text { criança/espaço }\end{array}$ & Relação criança/criança \\
\hline Escola & Casa \\
\hline
\end{tabular}

Levada às últimas consequências a influência da distinção entre tempo cíclico e linear na concepção de criança do Centro de Educação Infantil Aluysio de Menezes Greenhalg, teremos condições e recursos mais amplos para reformular com maior clareza um problema que permeou em todos os sentidos este artigo: se a educação é um processo de construção social da criança, por que aparece a todo o momento como natural? E se a educação é tida como natural, por que em nenhum momento a oposição essencial entre professor e crianças aparece como tal?

\section{Referências bibliográficas:}

DOUGLAS, Mary. Pureza e Perigo. São Paulo: Perspectiva, I996

DUMONT, Louis. "introdução”. In: Homo Hierarchicus. São Paulo: Edusp, I992.

EVANS-PRITGHARD, E. E. "Tempo e Espaço". In: Os Nuer. São Paulo: Perspectiva, 2000.

FOUGAULT, Michel. Vigiar e Punir. I3. ed., Rio de Janeiro: Vozes, I999.

GEERTZ, Clifford. "Pessoa, Tempo e Conduta em Bali". In: A interpretação das Culturas. Rio de Janeiro: LTG, I998. 
MAUSS, Marcel. "Uma Categoria do Gênero Humano: A Noção de Pessoa, a de 'Eu'”. In: Sociologia e Antropologia. São Paulo, Cosacnaify: 2007.

SIMMEL, Georg. "Indivíduo e Sociedade nas Concepções de Vida dos Séculos XVIII e XIX". In: Questões Fundamentais da Sociologia. Rio de Janeiro: Zahar, 2003.

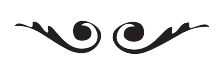

Marcio Bressiani Zamboni é graduando em Ciências Sociais na Usp.

E-mail: marciobz@gmail.com 